\title{
MAKING Up Political PeOPle: How SOCIAL MEDia CREATE THE IDEALS, DEFINITIONS, AND PROBABILITIES OF POLITICAL SPEECH
}

\author{
Mike Ananny* \\ Cite as: 4 Geo. L. Tech. ReV. 1 (2020)
}

TABLE OF CONTENTS

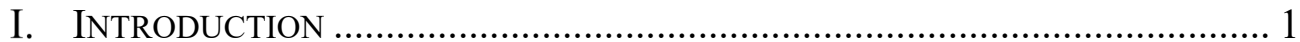

II. FACEBOOK'S FACT-CHECKING PARTNERSHIP AS INFRASTRUCTURE ........... 5

III. Three Ways Platforms See Public Life As/Through

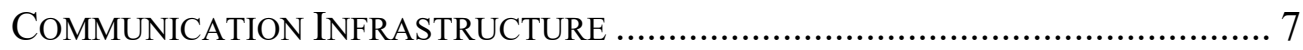

A. Information Ideals of Citizenship ........................................................ 7

B. The Categories of Politics and the Politics of Categories................... 9

C. Governing Scale through Probability................................................ 13

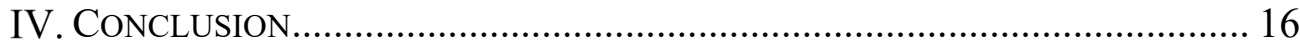

\section{INTRODUCTION}

Especially in the wake of the 2016 U.S. presidential election, there is increasing debate about how and why to regulate political speech posted on social media platforms, and whether such regulation is possible or desirable. Initially, such debates focused on the concept, production, and circulation of "fake news." As politicians like President Trump co-opted the term to attack

\footnotetext{
* Associate Professor at the University of Southern California's Annenberg School for Communication and Journalism; Ph.D., Stanford University, 2011. Thanks to: Prof Julie Cohen for the invitation to participate in and develop this article for Georgetown Law's conference "Election Integrity in the Networked Information Era;" Profs Erin Carroll and Julie Cohen for their thoughtful feedback; and the staff at the Georgetown Law Technology Review for their patient and helpful editorial guidance.

${ }^{1}$ See, e.g., M. Mitchell Waldrop, News Feature: The Genuine Problem of Fake News, 114 PROC. NAT'L ACAD. SCI. U.S. 12631 (2017).
} 
journalists and insulate themselves from criticism, ${ }^{2}$ and as academics argued against the term's imprecision, ${ }^{3}$ historical complexity, ${ }^{4}$ and political weaponization, ${ }^{5}$ this term fell out of favor. In lieu of discussing "fake news," scholars and public commentators gradually began talking about the role that "misinformation," "disinformation," or "computational propaganda" play in public discourse. ${ }^{6}$

Rarer, though, in debates about how to name and trace this problematic class of speech are more fundamental conversations about what type of public life is presumed or desired. More precisely: What types of public life does such a focus on truth or falsity take for granted, and what type of public life is created by focusing on the truth or falsity of information? While many scholars assume the existence of "fake news" as a powerful political phenomenon and focus on its spread, effects, and defenses, ${ }^{7}$ others have questioned the "myth of the attentive public" that fake news ostensibly harms, reminded us of persuasion campaigns' minimal effects, ${ }^{8}$ and questioned why scholars seem to be focusing on questions of information quality and circulation instead of longstanding political issues like race, class, and identity. ${ }^{9}$

In this paper, I want to depart slightly from scholarship that frames debates about contemporary, online political speech in terms of information, persuasion, effects, or even identity and instead ask: What assumptions do platform infrastructures make about public life, and what alternative forms of public life to do those assumptions foreclose? I focus on these infrastructures not because I see them as simple channels for delivering content that sways minds or elections, but because they are simultaneously instrumental and symbolic. Yes, they expose audiences to content, but they also serve as powerful sociotechnical imaginaries: "Collectively held, institutionally

\footnotetext{
${ }^{2}$ See Julia Sonnevend, Facts (Almost) Never Win over Myths, in TRUMP AND THE MEDIA 92 (Pablo Boczkowski \& Zizi Papacharissi eds., 2018).

${ }^{3}$ See generally Edson C. Tandoc Jr. et al., Defining "Fake News": A Typology of Scholarly Definitions, 6 DigITAL JoURNALISM 137 (2018).

${ }^{4}$ See generally Caroline Jack, Wicked Content, 12 COMM. CUlture \& CRITIQUE 435 (2019).

${ }^{5}$ See Joshua Habgood-Coote, Stop Talking About Fake News!, 62 INQUIRY 1033, 1034 (2019).

${ }^{6}$ See, e.g., Computational Propaganda (Samuel C. Woolley \& Philip N. Howard eds., 2018).

${ }^{7}$ See, e.g., David M. J. Lazer et al., The Science of Fake News, 359 SCIENCE 1094-96 (2018).

${ }^{8}$ David Karpf, On Digital Disinformation and Democratic Myths, Soc. SCI. RES. CouncIL: MEDiAWELL (Dec. 10, 2019), https://mediawell.ssrc.org/expert-reflections/on-digitaldisinformation-and-democratic-myths [https://perma.cc/2KR4-54JR].

${ }^{9}$ See DANiEl Kreiss, Prototype Politics 93-100 (2016).
} 
stabilized, and publicly performed visions of desirable futures" enacted through often invisible technologies. ${ }^{10}$

Science and Technology Scholars often focus on the public significance and power of built infrastructures - information systems and social arrangements that create the conditions under which collective meanings and public life are made. ${ }^{11}$ In the same tradition, I posit that today's dominant view of online political speech-and the dominant critiques thereof-rests on three largely unquestioned assumptions. Firstly, citizens are information processors and publics are information products. Secondly, public life rests on taken-for-granted categories that social media platforms have a vested interest in creating, naturalizing, and policing. Lastly, much of political speech is governed by largely invisible logics of probability that platforms use to justify a scale of data that their business models require.

To develop this argument and ground this critique, I focus on a partnership that Facebook formed with five U.S. news and fact-checking organizations in the wake of the 2016 U.S. presidential election. Drawing on interviews and fieldwork with key partnership participants, I show how this partnership was a form of political speech infrastructure that assumes an "information ideal" of citizenship, that rests upon proprietary and computed categories of political speech, and that uses probability as a tool to govern speech and as a rhetorical defense against the power of Facebook's scale.

Although a complete discussion of the concept is beyond the scope of this paper, I use the term "infrastructure" in the tradition of Science and Technology Scholars who largely define it as an often invisible set of relationships among people and materials (e.g., algorithms and databases) that create the conditions under which sociotechnical systems are seen to be working or failing. ${ }^{12}$ In addition to the more visible and formalized rules that govern organizations' and people's use of technologies, these relationships create the tacit norms, taken-for-granted practices, collective rhythms, shared terminology, and agreed-upon roles that make complex systems-from transport systems and power plants to advertising algorithms and sensor networks - seem stable, predictable, governable, and even boring. When such infrastructures are "inverted" 13 - when the usually invisible relations among their human and nonhuman actors are traced and analyzed-it becomes

${ }^{10}$ Sheila Jasanoff, Future Imperfect: Science, Technology, and the Imaginations of Modernity, in DreamsCAPES OF Modernity 1, 4 (Sheila Jasanoff \& Sang-Hyun Kim eds., 2015).

${ }^{11}$ See generally Christopher A. Le Dantec, Designing Publics (2016); Noortue MARRES, MATERIAL PARTICIPATION (2012).

12 See, e.g., Susan Leigh Star, The Ethnography of Infrastructure, 43 AM. BEHAV. SCIENTIST 377, 380-82 (1999).

${ }^{13}$ Geoffrey C. Bowker, SCIENCE ON THE RUN 104 (1994). 
possible to see how information systems are actually precarious, ongoing achievements that require a great deal of negotiation, coordination, and compromise. Infrastructures are anything but natural. They could be driven by different relationships, different definitions, and different tradeoffs. At any given moment, an infrastructure's form and function emerge from subtle and complex negotiations among people and machines, many of whom are not consciously aware of or reflecting upon the types of power, language, expertise, and values that are keeping their infrastructures alive. In light of Latour's claim that "technology is society made durable," 14 the concept of infrastructure becomes a way of (a) seeing technology as intertwined, mutually defining relationships between people and materials, and (b) asking which other societies might be possible, if only we had different relationships and different technologies.

Increasingly, scholars are using such an infrastructural lens to understand information work-everything from elections ${ }^{15}$, earthquakes, ${ }^{16}$ canals, ${ }^{17}$ and space exploration, ${ }^{18}$ to press freedom, ${ }^{19}$ artificial intelligence, ${ }^{20}$ television distribution, ${ }^{21}$ and fact-checking. ${ }^{22}$ This way of seeing technologies focuses little on the "effects" that media have on people. Instead, such an approach cares more about what kind of social, cultural, and public worlds are created though intertwined people and objects. In this vein, I not only claim that Facebook's partnership with news organizations can best be seen as infrastructural, I also want to read this infrastructure for the assumptions it makes about what public life is and should be.

${ }^{14}$ Bruno Latour, Technology Is Society Made Durable, in A Sociology OF Monsters: ESSAYS ON POWER, TEChNOLOGY, AND DOMINATION 103 (John Law ed., 1991).

${ }^{15}$ See generally KREISS, supra note 9.

${ }^{16}$ See generally MEgAn Finn, Documenting AFtermath (2018).

${ }^{17}$ See generally Ashley CARse, Beyond the Big Ditch: Politics, Ecology, AND INFRASTRUCTURE AT THE PANAMA CANAL (2014).

${ }^{18}$ See generally Janet Vertesi, Seamful Spaces: Heterogeneous Infrastructures in Interaction, 29 SCI. TECH. \& HuM. VALUES 264 (2014).

19 See generally Mike ANANNy, Networked Press FreEdom (2018).

${ }^{20}$ Kate Crawford \& Vladan Joler, Anatomy of an AI System: The Amazon Echo as An Anatomical Map of Human Labor, Data, and Planetary Resources, AI Now INST. \& SHARE LAB (2018), https://anatomyof.ai [https://perma.cc/A2NH-EWHL].

${ }^{21}$ See generally Joshua A. Braun, This Program is Brought to You By (2015).

${ }^{22}$ Lucas Graves \& C.W. Anderson, Discipline and Promote: Building Infrastructure and Managing Algorithms in a 'Structured Journalism' Project by Professional Fact-Checking Groups, 22 NEW MEDIA \& SOC’Y 342, 343 (2020). 


\section{FACEBOOK’s FACT-CHECKING PARTNERShIP AS INFRASTRUCTURE}

I base the analysis in this claim and this reading on a case study I conducted of Facebook's partnership with five U.S. news and fact-checking organizations. ${ }^{23}$ The partnership has since received significant journalistic attention, has changed, and is, in many ways, no longer the same network that I studied in 2017-2018. The point of this paper, though, is neither to give a cotemporaneous account of the network as it exists today, nor to evaluate the partnership's success or its impact on the spread of misinformation. Rather, my aim is to use the network as an object to think with about how a major social media platform understands political speech, sees its public purpose, and configures its infrastructures in ways that make some types of public life more or less possible.

My 2018 report gives fuller context on the partnership's origins and dynamics, but it is sufficient here to say that the collaboration was formed in the immediate aftermath of the 2016 U.S. presidential election, spurred on by a combination of factors. ${ }^{24}$ Whether the effect of its misinformation on the election was real or imagined, Facebook was caught in a major public relations scandal as people inside and outside of the company called for some kind of change to how the platform circulated content. At about the same time, the International Fact-Checking Network (IFCN) - a unit of the Poynter Institute that convenes fact-checkers worldwide-wrote an open letter calling for Facebook to provide more transparency and accountability in how it circulated misinformation. Facebook and five U.S. news and fact-checking organizations that were signatories to the IFCN's code of principles formed a partnership in which fact-checkers could "identify a story [that appeared on Facebook] as fake," flag that story as "disputed," and provide a "link to the corresponding article explaining why." 25 Stories that fact-checkers flagged as disputed could then potentially "appear lower in News Feed." 26 Fact-checkers were hungry for access to the raw materials that they needed for their work-

\footnotetext{
${ }^{23}$ Mike Ananny, The Partnership Press: Lessons for Platform-Publisher Collaborations as Facebook and News Outlets Team to Fight Misinformation, TOW CTR. FOR DIGITAL JOURNALISM (Apr. 4, 2018), https://www.cjr.org/tow_center_reports/partnership-pressfacebook-news-outlets-team-fight-misinformation.php [https://perma.cc/C47U-EUV6].

${ }^{24}$ See id.

${ }^{25} \mathrm{Id}$.

${ }^{26}$ Adam Mosseri, News Feed FYI: Addressing Hoaxes and Fake News, FACEBOOK Newsroom (December 15, 2016), https://newsroom.fb.com/news/2016/12/news-feed-fyiaddressing-hoaxes-and-fake-news/ [https://perma.cc/ZU9Y-4RQ9].
} 
misinformation - and one of the principal suppliers of those materialsFacebook-was offering them a type of insider access. ${ }^{27}$

This workflow was structured around a dashboard that Facebook built and then let its fact-checking partners access. ${ }^{28}$ Fact-checkers loaded the dashboard and reviewed the list of stories that Facebook had posted to it (based on "reports from [their] community, along with other signals"). The dashboard organized the stories in various ways, including by date, URL, and a "popularity" score that fact-checkers said Facebook never fully explained to them. Fact-checkers would choose a story to investigate, write their report, and then append their report to that story's dashboard entry. From there, Facebook would analyze the stories, the fact-check report, and other undisclosed signals. Some news organizations had a dedicated person responsible for choosing stories to fact-check off the Facebook dashboard, while other news organizations shared the role among multiple people. All partners stressed that they treated this content no differently than other stories they fact-checked. In a leaked email obtained by Buzzfeed News - later confirmed by Facebook ${ }^{29}$ the company claimed that "once we receive a false rating from one of our fact checking partners, we are able to reduce future impressions [of that story] on Facebook by 80 percent." 30

The partnership suffered from several challenges. For example, factcheckers debated amongst themselves whether and how much money to accept from Facebook for participating in the collaboration. ${ }^{31}$ Additionally, the dashboard and workflow were routinely critiqued as opaque and overwhelming; the dashboard listed thousands of stories, and fact-checkers felt that their methodical practices were too slow for the deluge. ${ }^{32}$ Factcheckers further complained that they knew too little about the impact of their work, that there was ambiguity regarding why certain sources but not others appeared on the dashboard, and that Facebook did not communicate with them often or clearly enough. ${ }^{33}$

27 See Ananny, supra note 23.

${ }^{28}$ Although I was never allowed to see the dashboard, the description of it here was confirmed by multiple partners. See id.

${ }^{29}$ Tessa Lyons, Hard Questions: What's Facebook's Strategy for Stopping False News?, FACEBOOK (May 23, 2018), https://about.fb.com/news/2018/05/hard-questions-false-news [https://perma.cc/A4GD-JCJC].

${ }^{30}$ Craig Silverman, Facebook Says Its Fact Checking Program Helps Reduce the Spread of a Fake Story By 80\%, BuzzFeEd News (Oct. 11, 2017), https://www.buzzfeednews.com/article/craigsilverman/facebook-just-shared-the-first-dataabout-how-effective-its [https://perma.cc/9XJ4-XGTS].

31 Ananny, supra note 23.

32 Id.

${ }^{33}$ Id. 
Although the partners worked to ameliorate several of these issuesand some partners left while others were added-it was clear that the partnership was infrastructural. It entailed norms, practices, and values among a variety of actors. Automated machine processes served up disputed stories, pushed the fact-checks back into an unseen system, and then reduced the circulation of those stories. The dashboard organized work and spurred debates and, unless you were the Facebook engineer who built the dashboard or the fact-checker who used it, much of the partnership was beyond your view, control, or even knowledge. Despite the attention it periodically received in the mainstream media and Facebook's public touting of its success in curbing misinformation, the partnership was largely invisible to most people. Just as most train passengers think little about railroad ties and few Netflix watchers think about the broadband networks enabling their binges, the fact-checking partnership became part of the largely invisible speech infrastructure that heavily influences what gets said, who hears it, and whether it is believed, shared, and acted upon.

\section{Three Ways Platforms See Public Life As/Through COMMUNICATION INFRASTRUCTURE}

\section{A. Information Ideals of Citizenship}

The infrastructure of Facebook's fact-checking partnership had many rich dynamics. In particular, this paper will focus on three things that the partnership - and platforms more generally-teaches us: How political communication technologies (1) see people, (2) defend categories, and (3) assume scales. To construct a normative critique of contemporary political communication - to ask if society is creating the kinds of publics that it wants and needs - one must develop precise interrogations of the infrastructures that structure political speech.

The fact-checking partnership was driven by an image of the ideal political person that mirrors what media historian Michael Schudson calls the "good citizen." ${ }^{34}$ Emerging out of late nineteenth- and early twentieth-century progressive moments, this was a "citizenship of intelligence rather than passionate intensity" 35 that foregrounded individual literacy and disciplined self-education- "a shift from sentiment to interest as the basis of politics." 36

\footnotetext{
${ }^{34}$ Michael Schudson, The Good Citizen 182 (David Batstone \& Eduardo Mendieta eds., 1998).

${ }^{35} \mathrm{Id}$

${ }^{36} \mathrm{Id}$. at 185 .
} 
This version of the good citizen is echoed in progressive models of journalism and deliberative theories of democracy that aim to give citizens the "objective" information that they need to vote, hold public officials accountable, and rationally debate policy alternatives. ${ }^{37}$ Indeed, fact-checking cultures often play into this information ideal by seeing themselves as verifiers of truths that citizens can use in whatever ways they like. ${ }^{38}$

I heard exactly this ideal of the citizen in how partners talked about the partnership and their work. Fact-checkers spoke of their need to get at the massive amounts of misinformation that Facebook indexed, their investment in "truthful reporting," and their desire to "reduce deception in politics." Facebook said that it "cannot become arbiters of truth ourselves," but could instead use the partnership as a way to "help people decide for themselves what to trust and what to share." 39 Fact-checkers and Facebook saw themselves as information brokers whose job was to increase the quality and validity of information circulating online. ${ }^{40}$

With only a small amount of dissent, fact-checkers and Facebook agreed that the misinformation its partnership identified should not be banned entirely from the platform (or the broader Internet). ${ }^{41}$ Some suggested that misinformation should be moved to an area separate from Facebook's main newsfeed, while others stressed that if misinformation was presented alongside fact-checks then people could decide for themselves what to make of the stories. They all largely adopted a marketplace model of political speech. One fact-checker said that that people's "motivation for sharing might be complicated . . . and [we] don't want to police the Internet." ${ }^{42}$ Another argued that as long as fact-checks accompanied misinformation, people would learn what was true, and as "a First Amendment supporter I find that cool." 43

The partnership's dominant image was of "good citizens" critically informing themselves, publics rationally debating quality information, and speech marketplaces surfacing truths. This image of the literate, rational, information-exchanging citizen, though, aligns poorly with (a) how effectively

\footnotetext{
37 See, e.g., Michael Schudson, Why Democracies Need an Unlovable Press 12 (2008).

38 Lucas Graves, Deciding What's True: The Rise of Political Fact-Checking in AMERICAN JOURNALISM 183 (2016).

${ }^{39}$ Mosseri, supra note 26.

${ }^{40}$ See Ananny, supra note 23.

${ }^{41} \mathrm{Id}$

${ }^{42} \mathrm{Id}$.

${ }^{43} \mathrm{Id}$.
} 
emotional political content drives social media popularity ${ }^{44}$ and (b) the prominence of the "popularity" metric in the partnership's own dashboard. Platforms thrive on emotional content, so it is unsurprising that "popularity" would be one of the dashboard's keywords.

It could be that partners thought that their fact-checking could counter the popularity of emotional political content-i.e., they knew that citizens are not rational information processors, but they wished they were and were trying to make them such by debunking popular misinformation. This wish contradicts a larger point made by scholars of evocative media, ${ }^{45}$ affective publics, ${ }^{46}$ and agonistic politics: ${ }^{47}$ Political emotion is immutable and sometimes desirable. Instead of trying to curb emotional content and make people into something they are not - a fool's errand given social media's love of affective engagement-partnerships and infrastructures like Facebook's might acknowledge the immutability of emotion and instead ask how affective media could create public life that $i s$ defensible and desirable.

B. The Categories of Politics and the Politics of Categories

The information ideal of citizenship is not the only contingent and contentious concept underpinning the partnership and social media more generally. Facebook and other platforms rely heavily on several largely opaque and unexplored definitions and categories that are made to seem like natural and essential elements of online political speech.

The most central term is, in fact, a collection of terms related to falsity. In a single 2018 policy statement, Facebook product manager Tessa Lyons uses several seemingly interchangeable terms, including "false news,"

\footnotetext{
${ }^{44}$ See Porismita Borah, Political Facebook Use: Campaign Strategies Used in 2008 and 2012 Presidential Elections, 13 J. INFO. TECH. \& Pol. 326, 329-30 (2016); William J. Brady et al., Attentional Capture Helps Explain Why Moral and Emotional Content Go Viral, 149 J. EXPERIMENTAL PSyCHOL.: GEN. 746, 746-47; Manon Metz et al., Personalization of Politics on Facebook: Examining the Content and Effects of Professional, Emotional, and Private Self-Personalization, INFO. COMM. \& SOC'Y 1, 12-13 (Feb. 20, 2019), https://www.tandfonline.com/doi/abs/10.1080/1369118X.2019.1581244 [https://perma.cc/Z45V-6AJ3].

${ }^{45}$ See generally Karin Wahl-Jorgenson, Emotions, Media, And Politics (2019).

${ }^{46}$ See Zizi Papacharissi \& Maria de Fatima Oliveira, Affective News and Networked Publics: The Rhythm of News Storytelling on \#Egypt, 62 J. COMM. 266, 280 (2012).

${ }^{47}$ See generally Chantal Mouffe, On THe Political (2005).
} 
"misinformation," "fake stories," "inauthentic content," and "misleading content." $" 48$ There is little clarity or precision in Facebook's language. ${ }^{49}$

To be sure, the phenomenon is by no means obvious or incontrovertible. Lucas Graves, one of the leading scholars of journalistic factchecking, describes how messy and interpretive the practice can be. He finds that fact-checking is anything but a quick verification of pre-existing claims. ${ }^{50}$ Instead, it is a form of knowledge production in which "simple and settled questions seem to become more complicated and less settled on closer inspection," as fact-checkers weigh different types of authority and expertise, consider incomplete and uncertain information, and interpret the assumptions and expectations of different audiences. ${ }^{51}$ Rarely do fact-checkers encounter the kind of neat ontological categories that platforms and machine learning algorithms assume. Facebook has a vested interest in outsourcing uncertainty to fact-checkers, whose judgments they can use to "improve our technology so we can identify more potential false news faster in the future." 52 Though self-reflective fact-checkers know that their determinations can be contingent and contextual, Facebook requires "true" or "false" to be stable categories policed by professionals whom the platform can lean on for the legitimacy it needs to claim that its circulation of political speech is neutral and objective.

Fact-checkers balked, though, at one of the dashboard's central categories: "Popularity." As one fact-checker said, "We've asked [Facebook] a hundred ways to Sunday what 'popularity' means. We don't know the mechanism they use to determine popularity." 53 Several fact-checkers questioned why they never saw widely popular mainstream news or conservative conspiracy sites like InfoWars listed on the dashboard. ${ }^{54}$ Factcheckers also wondered whether they were missing important forms of misinformation that did not fit with Facebook's calculation of "popular," and speculated (without evidence) that Facebook might not define as "popular" stories that earned the platform a great deal of advertising revenue. ${ }^{55}$ Partly in response to partners' concerns, Facebook added an "impact" metric to the

\footnotetext{
${ }^{48}$ Lyons, supra note 29.

49 See id.

${ }^{50}$ GrAVES, supra note 38 , at 69.

${ }^{51} \mathrm{Id}$.

52 Lyons, supra note 29.

53 Ananny, supra note 23.

${ }^{54} \mathrm{Id}$.

${ }^{55} \mathrm{Id}$.
} 
dashboard, though fact-checkers similarly did not understand how this term was defined. ${ }^{56}$

But even though fact-checkers questioned these terms and calculations, they seemed simultaneously grateful for them. They knew that popularity was an important phenomenon and seemed willing to let Facebook own the operationalizations of these concepts, or simply accepted that they could never persuade Facebook that such calculations were proprietary trade secrets that could not be discussed in detail. One fact-checker expressed gratitude to Facebook for "doing that work, providing views on what's popular, what's circulating." ${ }^{57}$ And another acknowledged that even imperfect popularity metrics helped them allocate their time: ${ }^{58}$ "You don't want to write about something that hasn't gone viral because you don't want to elevate its visibility. But if there's something that is being widely circulated, then you want to debunk it." 59

These debates about "true" versus "false," "inauthentic" versus "verified," and the meaning of "popular" are only a small part of Facebook's larger assumptions about the stability and incontrovertible aspects of political speech. For example, in his 2019 speech outlining the platform's work to "prevent outside interference in elections and Facebook's attitude towards political speech," Facebook Vice President of Global Affairs and Communications (and former Deputy Prime Minister of the UK) Nick Clegg foregrounded — but left undefined — an almost endless number of key terms. ${ }^{60}$ Those terms included "politician" (does this include officeholders and office-seekers at all levels of government?), "newsworthy" (it depends upon the content's "public interest value" and whether a region has a "free press"), "election" (it is unclear when Facebook thinks these start and stop), and "deepfake" videos (versus shallowly faked forms of other media that are presumably less newsworthy or of lower public value). ${ }^{61}$

To be sure, these terms are unstable and not easy to define. They shift depending on the context and the different values and assumptions of the speaker, and they are the subject of endless scholarly debate. My concern is not that Facebook has defined these terms incorrectly_ people can and should

\footnotetext{
56 Id.

${ }^{57} \mathrm{Id}$.

${ }^{58} \mathrm{Id}$.

${ }^{59} \mathrm{Id}$.

${ }^{60}$ Nick Clegg, Facebook, Elections and Political Speech, FACEBOOK NEWSROOM (Sept. 24, 2019), https://about.fb.com/news/2019/09/elections-and-political-speech [https://perma.cc/9XZV-Q9SR].

${ }^{61}$ See id.
} 
disagree about them-but rather that Facebook has created operationalizations of these terms through largely opaque and poorly understood processes. Further, the inaccessibility these terms places them not only beyond critique - they become baked into the infrastructures of online political speech - but they can become naturalized in a way that gives them an entirely new type of political power. To function at the scale that its business model requires, Facebook needs to conceal its definitional work-to be sure, the platform's public power and opacity is a problem - but my deeper concern is that Facebook is creating a seemingly natural set of terms and definitions that will become dominant categories of political speech and, thus, the categories used for collective self-governance. It is one thing not to be able to see inside the machinery that operationalizes and governs political speech, but it is quite another not to be able to debate the meaning of words like politician, newsworthy, public interest, or free press - or even know what words and categories make the platform work.

Facebook is not alone in making these categorical assumptions. News organizations often breezily switch between calling their audiences "users" versus "readers;" Twitter describes its "trending topics" as a neutral image of people's interests, Google maintains a private whitelist of websites that it judges worthy of indexing on Google News, and journalists themselves often equate tweets and search-engine queries with "public opinion." ${ }^{2}$ The space of politics shrinks when we fail to acknowledge the politics of political categories.

This debate is not new. In her foundational paper "Do Categories Have Politics?" Science and Technology Scholar Lucy Suchman identified a class of "coordination technologies" that "provide canonical frameworks for the representation and control of everyday communication practices." ${ }^{\prime 3}$ Her concern was that such technologies were based on a set of uncritiqued and largely invisible models that aimed to "discipline and control" people's actions. ${ }^{64}$ After Suchman used Terry Winograd's system to illustrate her argument, Winograd, doctoral advisor to Google co-founder Larry Page and later a company advisor, responded by largely dismissing her core critique as "sociopolitical drama," 65 but accepted that no system can "fully capture the

\footnotetext{
${ }^{62}$ Shannon C. McGregor, Social Media as Public Opinion: How Journalists Use Social Media to Represent Public Opinion, 20 JouRNALISM 1070, 1071 (2019).

63 Lucy Suchman, Do Categories Have Politics? The Language Action Perspective Reconsidered, 2 COMPUTER SUPPORTED COOPERATIVE WORK 177, 178 (1994).

${ }^{64} \mathrm{Id}$.

65 Terry Winograd, Categories, Disciplines, and Social Coordination, 2 COMPUTER SUPPORTED COOPERATIVE WORK 191, 191 (1994).
} 
richness of mental life or social interaction."66 Standardization and coordinated action were essential if distributed activities were to accomplish a goal. ${ }^{67}$ Winograd's solution to Suchman's charge was to invite people to participate in the creation of computational systems, arguing that "design succeeds when it is grounded in the context and experience of those who live in the situation." 68

The problem with Winograd's response to Suchman's astute critique is that those of us who "live in the situation" that Facebook creates-who are "grounded in the context and experience" of the political speech the platform governs - often cannot see, understand, consent to, or counter its categories and definitions. The deep challenge is not only accessing these terms and holding those who dominate the political life that they describe accountable, but fighting against their privatization and naturalization.

\section{Governing Scale through Probability}

Touting the success of the fact-checking partnership, Lyons, the Facebook product manager, said that when partners "rate something as false, we rank those stories significantly lower in News Feed. On average, this cuts future views by more than $80 \%$." ${ }^{69}$ Several fact-checkers said that they were unsure what to make of this statistic, replying, "I don't know how that number is calculated," "We have no public proof of that," and, ironically, "I can't factcheck that claim, and that's a problem."

Regardless of whether the statistic is true, it points to a larger dimension of how social media understands the regulation of political speech. Instead of banning misinformation or deleting problematic content, Facebook and other social media platforms rely instead on a probabilistic model of speech regulation. They never promise that users will not see content, they just say that it will be less likely. This rationale seemed to frustrate fact-checkers. It points to a new, probabilistic way to treat fact-checkers' work that they did not fully understand or agree with. "We don't get any information about these stories or what's happened to them [after we fact-check them]. What they're telling the public is no more than what we're getting. We don't know and we don't understand how they're using it." ${ }^{\text {"71 }}$

\footnotetext{
${ }^{66}$ Id. at 192.

${ }^{67} \mathrm{Id}$.

${ }^{68} \mathrm{Id}$. at 195.

${ }^{69}$ Lyons, supra note 29.

70 Ananny, supra note 23.

${ }^{71} \mathrm{Id}$.
} 
This probabilistic gray area was new because it was unlike how factcheckers saw the value of their work and a different kind of debate than the one they were accustomed to. Fact-checkers told me that they were used to a debate about whether false information should be banned from a platform entirely (de-indexed and entirely removed as best the platform could) or whether false information should continue to appear but displayed alongside the fact-check. Some fact-checkers favored outright bans, others suggested that false information be placed in a separate area, and still, others were comfortable with their fact-checks appearing alongside false information. ${ }^{72}$ But no one knew what to do with Facebook's regulation-through-probability. Why was the $80 \%$ number celebrated? How were the remaining $20 \%$ of views distributed? Who was still seeing the content, and was it better or worse that they saw it more or less often than others? In his speech, Clegg said that Facebook would "demote" (not ban) "previously debunked content" that "politicians" shared ${ }^{73}$ so was the Facebook the $80 \%$ statistic the same number that would drive those demotions? Were there different percentages for politicians and non-politicians (however each is defined)? Did 80\% represent a victory that satisfied Facebook, a target that their algorithms were trying to hit, or was it trying to move to a different number- $85 \%$ ? $90 \%$ ? $97 \%$ ? Presumably, the target is not $100 \%$, because that would be a ban, and Facebook's then-vice president for its News Feed product said "that we cannot become arbiters of truth ourselves." "74 To Facebook, probabilities are governors, but not arbiters. They seem to see themselves as creating statistical likelihoods that exist below some threshold of chance that does not act as a deterministic judgment.

As with the discussion of political categories, the point here is not to advocate for an ideal number or to say that Facebook is succeeding or failing with this statistic. Rather, what emerged through the partnership was the idea that speech should be governed probabilistically, that fact-checkers' work would somehow feed into those likelihoods in ways that they did not understand and could not verify, and that this type of statistical, algorithmic governance was less odious to the circulation of political speech than some other system would be.

I elsewhere discuss how this type of probabilistic governance is not unique to Facebook and suggest that it is a new and understudied logic

\footnotetext{
${ }^{72} \mathrm{Id}$.

${ }^{73}$ Clegg, supra note 60.

${ }^{74}$ Mosseri, supra note 26.
} 
common to many online platforms ${ }^{75}$ For example, in 2019, YouTube said it would "begin reducing recommendations of borderline content and content that could misinform users in harmful ways." ${ }^{76}$ Twitter's Del Harvey said that, "Given the context of the scale we're dealing with, if you're talking about a billion tweets, and everything goes perfectly right $99.999 \%$ of the time, then you're still talking about 10,000 tweets where everything might not have gone right." 77 And, after the ACLU discovered that Amazon's Rekognition facial recognition system falsely identified twenty-eight members of the U.S. Congress as felons, the company said that it recommended that developers of law-enforcement applications set its API match metric at "a threshold of at least $95 \%$ or higher," instead of the API's default $80 \%$ confidence level. ${ }^{78}$

Platforms' business models need a scale that is ungovernable by anything other than statistical techniques. Although platform antitrust initiatives continue apace, it is inconceivable that all of the large-scale social media platforms will be broken up and become small enough for exclusively human curation and moderation. Given that scale is here to stay, it seems imperative that governance mechanisms like probabilistic speech regulation receive greater critical attention. How are such thresholds, probabilities, and confidence intervals set? Are they explicit, humanly set limits, or are the variable outputs of machine learning systems designed to find different kinds of patterns? What happens when categories and probabilities intersect-e.g., when the likelihood of a video being a "deepfake" needs to be compared against the chance that bots are circulating a video, which has been shared with by someone who behaves "like" a politician, in a country that "usually" enjoys "press freedom?" As we try to protect the circulation of "political speech" during "elections," what thresholds and confidences do we need to meet for people to see those races as legitimate? The complexities of probabilistic governance quickly spiral beyond comprehension and control. Is it possible to understand probabilistic systems well enough to slow their spirals?

\footnotetext{
${ }^{75}$ Mike Ananny, Probably Speech, Maybe Free: Toward a Probabilistic Understanding of Online Expression and Platform Governance, KNIGHT FIRST AMEND. InST. (Aug. 21, 2019), https://knightcolumbia.org/content/probably-speech-maybe-free-toward-a-probabilisticunderstanding-of-online-expression-and-platform-governance [https://perma.cc/T7BC2QX8].

${ }^{76}$ Continuing Our Work to Improve Recommendations on YouTube, YouTuBE: OfFICIAL BLOG (Jan. 25, 2019), https://youtube.googleblog.com/2019/01/continuing-our-work-toimprove.html [https://perma.cc/68XL-V69J].

77 Tarleton Gillespie, Platforms Are Not Intermediaries, 2 GEO. L. TECH. REV. 198, 198 n.1 (2018).

${ }^{78}$ Davey Alba, Amazon Rekognition Falsely Matched 28 Members of Congress with Arrest Mugshots, BUZZFEED NEws (July 26, 2018, 2:32 PM), https://www.buzzfeednews.com/article/daveyalba/amazon-rekognition-facial-recognitioncongress-false [https://perma.cc/H5P6-BWE5].
} 


\section{CONCLUSION}

Politics often involves fighting about ideals, categories, and impacts. The type of politics unfolding in online environments is no different, except the ideals, categories, and impacts of contemporary, networked politics are playing out in infrastructures. Private, self-regulating corporations largely control these infrastructures. Even platform employees with full access find it difficult to trace and understand them. And scholars are only beginning to develop the techniques needed to critique the precise ways that speech infrastructures make some speech, and some forms of public life, more likely and desirable than others.

This all matters because, although there is a great deal of smart conversation about how and why to regulate platforms, there does not seem to be as much deep thinking about what kind of public life platform regulations aim to create. Is the ideal public a rational, deliberative, truth-seeking one that Facebook and its fact-checkers seem to want? Is it a participatory one that is less concerned about truth and more concerned about the exchange of opinions? Is it an aggregation of responses to polls, surveys, and questionnaires? Is it an agonistic one that cultivates disagreement, and manages shared consequences, without ever thinking that anything like consensus is ever possible? In all likelihood, it is some combination of these, but it is well past time to create platform regulations that move beyond an almost exclusive focus on marketplace models of speech and deliberative ideals of the public, to messier and normatively complex images of the public interest. $^{79}$

One of the places that these images of public life appear is in the media infrastructures that govern online speech. These infrastructures are messy, hidden, and seemingly boring things like content dashboards ${ }^{80}$ structured data formats, ${ }^{81}$ political relationship management systems, ${ }^{82}$ and news advertising networks. ${ }^{83}$ Though journalism scholars are beginning to interrogate the epistemological dynamics of these infrastructures ${ }^{84}$ - how they make and

\footnotetext{
${ }^{79}$ See generally Phillip M. NAPOli, Social Media And the Public InTERest (2019).

${ }^{80}$ See Caitlin Petre, Engineering Consent, 6 Digital Journalism 509, 510 (2018).

${ }^{81}$ See Graves \& Anderson, supra note 22, at 347.

${ }^{82}$ See, e.g., Fenwick McKelvey, Cranks, Clickbait and Cons: On the Acceptable Use of Political Engagement Platforms, 8 INTERNET POL'Y REV. 1, 2 (2019).

${ }^{83}$ Joshua A. Braun \& Jessica L. Eckland, Fake News, Real Money: Ad Tech Platforms, ProfitDriven Hoaxes, and the Business of Journalism, 7 Digital Journalism 1, 1 (2019).

${ }^{84}$ See, e.g., Matt Carlson, Journalistic Epistemology and Digital News Circulation: Infrastructure, Circulation Practices, and Epistemic Contests, 22 News MediA \& SoC'y 230,
} 
circulate knowledge claims - there is still little work on these infrastructures' normative power - their ability to "make up people" and the rules of politics and thus create public life.

I have tried to show here that there are (at least) three ways of making up political people: By implicitly adhering to an information ideal of the citizen and a marketplace model of speech, by letting platforms create and naturalize the terms and categories that political life depends upon, and by uncritically accepting the probabilistic governance systems that the business models of large-scale social media platforms seem to need.

To imagine different kinds of publics and sociotechnical futures-e.g., to see press freedom differently ${ }^{85}$ or create public media systems ${ }^{86}$ - we need to reject exclusively information-based ideals of political personhood, denaturalize social media categories, and trace, resist, and perhaps ban probabilistic governance that is beyond human oversight.

232 (2020); Jonathon Gray et al., 'Fake News' as Infrastructural Uncanny, 22 NEWs \& MEDIA 317,324 (2020).

${ }^{85}$ See generally ANANNY, supra note 19.

${ }^{86}$ See generally Victor PickARD, DEMOCRACY Without JoURnALISM? CONFRONTING THE MISINFORMATION SOCIETY (2020). 